\title{
Fungal infections in lung transplantation
}

\author{
Palash Samanta ${ }^{1}$, Cornelius J. Clancy ${ }^{2,3}$, M. Hong Nguyen ${ }^{1,2,3}$ \\ ${ }^{1}$ University of Pittsburgh Medical Center, Pittsburgh, PA, USA; ${ }^{2}$ Department of Medicine, University of Pittsburgh, Pittsburgh, PA, USA; ${ }^{3}$ Clinical \\ and Translational Science Institute, University of Pittsburgh, Pittsburgh, PA, USA \\ Contributions: (I) Conception and design: None; (II) Administrative support: None; (III) Provision of study materials or patients: None; (IV) \\ Collection and assembly of data: None; (V) Data analysis and interpretation: None; (VI) Manuscript writing: All authors; (VII) Final approval of \\ manuscript: All authors. \\ Correspondence to: M. Hong Nguyen. University of Pittsburgh, Scaife Hall, Suite 869, 3550 Terrace Street, Pittsburgh, PA 15261, USA. \\ Email: mhn5@pitt.edu.
}

\begin{abstract}
Lung transplant is a potential life-saving procedure for chronic lung diseases. Lung transplant recipients (LTRs) are at the greatest risk for invasive fungal infections (IFIs) among solid organ transplant (SOT) recipients because the allograft is directly exposed to fungi in the environment, airway and lung host defenses are impaired, and immunosuppressive regimens are particularly intense. IFIs occur within a year of transplant in 3-19\% of LTRs, and they are associated with high mortality, prolonged hospital stays, and excess healthcare costs. The most common causes of post-LT IFIs are Aspergillus and Candida spp.; less common pathogens are Mucorales, other non-Aspergillus moulds, Cryptococcus neoformans, Pneumocystis jirovecii, and endemic mycoses. The majority of IFIs occur in the first year following transplant, although later onset is observed with prolonged antifungal prophylaxis. The most common manifestations of invasive mould infections (IMIs) include tracheobronchial (particularly at anastomotic sites), pulmonary and disseminated infections. The mortality rate of tracheobronchitis is typically low, but local complications such as bronchomalacia, stenosis and dehiscence may occur. Mortality rates associated with lung and disseminated infections can exceed $40 \%$ and $80 \%$, respectively. IMI risk factors include mould colonization, single lung transplant and augmented immunosuppression. Candidiasis is less common than mould infections, and manifests as bloodstream or other non-pulmonary invasive candidiasis; tracheobronchial infections are encountered uncommonly. Risk factors for and outcomes of candidiasis are similar to those of non lung transplant recipients. There is evidence that IFIs and fungal colonization are risk factors for allograft failure due to chronic rejection. Mould-active azoles are frontline agents for treatment of IMIs, with local debridement as needed for tracheobronchial disease. Echinocandins and azoles are treatments for invasive candidiasis, in keeping with guidelines in other patient populations. Antifungal prophylaxis is commonly administered, but benefits and optimal regimens are not defined. Universal mould-active azole prophylaxis is used most often. Other approaches include targeted prophylaxis of high-risk LTRs or pre-emptive therapy based on culture or galactomannan (GM) (or other biomarker) results. Prophylaxis trials are needed, but difficult to perform due to heterogeneity in local epidemiology of IFIs and standard LT practices. The key to devising rational strategies for preventing IFIs is to understand local epidemiology in context of institutional clinical practices.
\end{abstract}

Keywords: Invasive fungal infection (IFI); lung transplant; antifungal prophylaxis

Submitted Jan 27, 2021. Accepted for publication Jul 14, 2021.

doi: $10.21037 /$ jtd-2021-26

View this article at: https://dx.doi.org/10.21037/jtd-2021-26 


\section{Introduction}

Lung transplantation (LT) has become a potential lifesaving procedure for a wide range of end-stage lung diseases. The number of LTs worldwide is increasing every year. In the USA alone, there were 2,714 LTs performed in 2019, a $7.3 \%$ increase from previous year and the highest yearly number to date (https://unos.org/data/transplant-trends/, https://optn.transplant.hrsa.gov/data/view-data-reports/ national-data/). Although LT increases the life span and quality of life of patients with advanced lung diseases, outcomes after LT remain inferior to those of other solid organ transplants (SOT). The median survival after LT is $78 \%$ and $51 \%$ at 1 -year and 5 -years, respectively (https:// www.nhlbi.nih.gov/node/3963). High incidence of rejection and infectious complications, especially within the first year of transplantation, contribute to high morbidity and mortality in lung transplant recipients (LTR). While advances in immunosuppressive regimens in the last decade reduced the rates of rejection and increased graft survival, these improvements came at the expense of increased rates of opportunistic infections. Invasive fungal infections (IFI) are frequent complications after LT, causing significant morbidity and up to 3 -fold increases in all-cause mortality $(1,2)$. In addition, IFIs lead to excess lengths of stay ranging from 13.6 to 23.5 days, and excess costs ranging from $\$ 44,243$ to $\$ 70,260$ depending on the transplant type $(3,4)$. Although antifungal prophylaxis is routinely administered in most LT centers in the USA, there is no consensus on the best agent, or optimal duration, and costeffectiveness of different antifungal prophylaxis strategies (5). In this review, we will discuss the epidemiology, clinical spectrum, risk factors, short- and long-term outcomes of IFI, and antifungal prophylaxis strategies in LTRs.

\section{Epidemiology and microbiology}

IFIs are among the most common opportunistic infections in LTR, with cumulative incidence of $3 \%$ to $19 \%$ within the first year of LT (1,6-10). These rates are second only to small bowel transplant recipients among all SOT (8). However, the epidemiology of IFIs in LTRs varies greatly between centers, as do LT practices (e.g., types of patient populations transplanted, transplant selection criteria at individual centers, and types of immunosuppression, antifungal prophylaxis and other post-transplant care) and regional environmental factors. Therefore, the first step in devising rational strategies to manage or prevent IFIs is to understand local epidemiology in the context of current practices.

The most common etiologic agents of IFI among LTRs are Aspergillus (44\%) and Candida (23\%) spp. Members of the Mucorales family (3\%), Cryptococcus neoformans (2\%), Pneumocystis jirovecii (2\%) and endemic dimorphic fungi (1\%) are less common (6,8,11-14) (Table 1). Among Aspergillus spp, A. fumigatus is the most common, with rates of IFIs ranging from $2 \%$ to $30 \%(15-17)$. Recent studies show emergence of non-Aspergillus moulds (e.g., Scedosporium apiospermum (most common), Fusarium spp, Mucorales spp., Paecilomyces spp. and Penicillium spp), which accounted for $28 \%$ of all IMIs $(8,10,18-21)$. IMIs due to non-Aspergillus moulds are more common among LTR than recipients of other SOTs, and they are associated with higher rates of dissemination and mortality than infections due to Aspergillus (8). In part, the higher mortality may be due to a propensity to antifungal resistance, which limits therapeutic options (6). A retrospective review of voriconazole and posaconazole breakthrough IFIs among SOT recipients and other immunosuppressed patients revealed a significant shift toward non-Aspergillus fumigatus moulds, including members of $A$. ustus complex, which exhibit relatively high azole MICs, multi-drug resistant moulds such as Lomentospora prolificans and Rasamsonia argillaceae, and intrinsically azole-resistant Scopulariopsis (22). Unlike data from Europe, azole-resistant $A$. fumigatus is uncommon in the US.

\section{Timeline of IFIs}

The majority of IFIs occur within the first year of LT (12). Invasive candidiasis generally occurs within the first 3 months following LT, but the rate is highest within the first month (12). Invasive mould infections (IMIs) can be divided into tracheobronchial tree (tracheobronchitis or anastomotic infection), lung parenchyma (pneumonia), and disseminated infections. The common etiologic agents causing IFI among LTR are summarized in Table 1 (1,6,7,913,15-17,19,20,23). Aspergillosis, the most common IMI, usually occurs within 1 year of LT, with the majority of infections occurring within the first 6 months (12). Tracheobronchial aspergillosis, which is more common in LTR than among other SOT recipients, is encountered most often within 3 to 6 months of LT (24-26); however, cases have been reported as late as 3 years post-transplant (27). Invasive pulmonary aspergillosis (IPA) generally occurs later than tracheobronchitis, at median 6 months after LT. Besides Candida and Aspergillus infections, 
Table 1 Pathogens causing IFIs in LTR

\begin{tabular}{lc}
\hline Organisms & Incidence range \\
\hline Yeasts & $3-11.4 \%$ \\
Candida spp & $0.66 \%$ \\
Cryptococcus spp & \\
Molds & $3-15 \%$ \\
Aspergillus spp & $0.28-4.8 \%$ \\
Mucorales group & \\
Endemic mycosis & $0.13 \%$ \\
Histoplasma spp & \\
Coccidiodomyces spp & \\
Blastomyces spp & $0.04 \%$ \\
Others & $0.02 \%$ \\
Fusarium spp & \\
Scedosporium spp & \\
Pneumocystis jirovecci & $0.24 \%$ \\
\hline
\end{tabular}

\#, incidence for all SOT recipients; *, the true incidence is unknown due to widespread use of anti-Pneumocystis prophylaxis. In the pre-prophylaxis era, incidence was as high as $15 \%$. IFI, invasive fungal infection; LTR, lung transplant recipient; SOT, solid organ transplant.

LTR are also at risk for cryptococcosis, which is caused by the opportunistic yeast Cryptococcus neoformans. Cryptococcosis is more common in LTR than other SOT recipients. The median time from transplant to onset of cryptococcosis is earlier (191 days; range, 7.5-1,816 days) in LTR than in other SOT recipients (464 days; range, 4-2,393 days) (23).

Less commonly, IMIs occur later than 1 year after LT. Although Aspergillus remains the most common etiologic agent, non-Aspergillus IMIs have emerged in this later period, especially among LT receiving prolonged antifungal prophylaxis (18). For example, the median times to Scedosporium infection and mucormycosis are 12 and 26 months post-LT respectively. Other IMIs, including those caused by Fusarium, Paecilomyces, Acremonium, Chrysosporium, Cladosporium, Exophiala etc., occur at median of 16 months (20).

\section{Spectrum of IFIs}

\section{Invasive candidiasis}

Candida spp. cause significant nosocomial infections (surgical site infections, sternal wound infection, empyema, catheterrelated bloodstream infections). More rarely, endobronchial candidiasis such as necrotizing bronchial anastomotic infections are encountered, especially in the presence of anastomotic dehiscence and bronchial stents $(10,28,29)$. Although Candida spp are common colonizers of the airways in LTR, pulmonary candidiasis is exceeding rare.

\section{IMIs}

LTRs are disproportionately susceptible to fungal tracheobronchitis, with disease incidence ranging from $5 \%$ to $25 \%(12,30,31)$. Aspergillus spp are the most common pathogens (tracheobronchial aspergillosis); other etiologic agents are non-Aspergillus moulds and Candida spp (24). Rare and severe cases of Mucorales tracheobronchitis have also been reported (32).

Tracheobronchial infections are diagnosed by bronchoscopy with presence of obstructing, ulcerative or necrotic bronchial lesions or pseudomembranes, and evidence of invasive fungal organisms on biopsy $(12,30,31)$. Ulcerative or necrotic lesions often occur around the suture line of anastomotic sites. Central airway obstruction is a form of fungal tracheobronchitis in which patients present with rapid drops in FEV1, and evidence of large, fibrinous Aspergillus-laden mucous plugs that respond to increased doses of corticosteroids and antifungal therapy (33). A necrotizing pseudomembranous form of invasive fungal tracheobronchitis is most severe, characterized by sloughed off necrotic epithelium and endobronchial mucous overlying the mucosal surface. This disease can lead to more invasive infections and dissemination (34). Invasive tracheobronchial aspergillosis (ITBA) may be asymptomatic and detected incidentally by surveillance bronchoscopy (35). ITBA is associated with a more favorable outcome in LTR than in other severely immunocompromised patients, since early diagnosis by routine bronchoscopy often prompts antifungal treatment before clinical symptoms occur. Complications of tracheobronchial aspergillosis can occur, including bronchomalacia, bronchial stenosis, dehiscence, hemorrhage and progression to parenchymal and disseminated disease.

The lungs are the most common site of IMIs. Fungal pneumonia is defined as radiographic evidence of nodules, cavities or pulmonary infiltrates with tissue invasion observed on histopathology, and isolation of the fungi from respiratory culture. IMIs are considered disseminated when disease is documented histopathologically in $\geq 2$ 
Table 2 Risk factors for IMI in LTR

Pre-transplant risk factors
Airway colonization with pathogenic moulds
History of IMI prior to LT
Peri-transplant risk factors
Induction therapy with thymoglobulin or alemtuzumab
Donor lung with pathogenic fungi
Anastomotic dehiscence
Renal replacement therapy
Environmental exposure
Post-transplant risk factors
Early/persistent airway ischemia
Airway colonization with pathogenic moulds
Ongoing allograft rejection and need for immune augmentation
Native lung as a source of infection in single LT
Viral infection: respiratory viruses, CMV infection
CLAD/BOS
Hypogammaglobulinemia

IMI, invasive mold infection; LTR, lung transplant recipient; LT, lung transplantation; CLAD, chronic lung allograft dysfunction; $\mathrm{BOS}$, bronchiolitis obliterans syndrome; CMV, cytomegalovirus.

non-contagious organ sites (13). Disseminated infections involving extrapulmonary sites such as central nervous system (CNS), bones and joints, large blood vessels can occur, but they are relatively uncommon.

\section{Risk factors for IFIs}

LTRs are at higher risk of developing IFI compared to other SOT recipients for several reasons. First, allograft lungs are directly exposed to moulds that are ubiquitous in the environment. Second, pulmonary host defenses are impaired after LT due to decreased cough reflex from lung denervation, abnormal mucociliary clearance, and disruption of lymphatic drainage. Third, since the bronchial artery is transected during donor lung harvest, the allograft airway and anastomotic site depend on collateral blood supply until revascularization is established (36). Thus, respiratory pathogens have particularly propensity for the bronchial anastomotic site, especially within the first 4-6 weeks after transplant, before vascular collaterals develop (37). Impaired blood flow also impedes the penetration of antifungal drug in the airway. Lastly, LT immunosuppression regimens are more intense than those of other SOTs, and typically involve lifelong three-drug therapy.

Airway colonization is a pre-requisite of subsequent IMIs, both early and late after LT. At any time after LT, the cumulative incidence of mould airway colonization ranges between $20 \%$ and 50\% (38,39). Aspergillus spp. are the most common colonizers; up to $23 \%$ of LTRs have Aspergillus airway colonization $(38,39)$. Mould colonization at the time of LT is a well-established risk factor for IMI within 3 months (early onset) (40-43). Overall, approximately $8 \%$ and $4 \%$ of LT candidates are colonized pre-LT with pathogenic fungi (mould and dimorphic fungi) and Aspergillus spp., respectively $(3,44)$. The rate of Aspergillus colonization is much higher among patients with cystic fibrosis. In one study, $70 \%$ of patients with cystic fibrosis had pre-transplant Aspergillus colonization, and 39\% had Aspergillus recovered from intra-operative bronchoalveolar fluid (43). IMI was found in explanted lung histopathology in $5 \%$ of LTRs; in $57 \%$ of these cases, IMIs were not diagnosed or suspected pre-transplant (45). IMI of explanted lungs at the time of transplant was associated with a significantly higher risk of IMI and mortality postLT (45). Colonization with pathogenic moulds is also a risk factor for late-onset IMI. Other factors leading to lateonset IA include age, augmentation of immunosuppression and bronchiolitis obliterans syndrome (BOS) (46-49). Single lung transplant has also been linked to IMI. Risk factors that are found in some studies but not in others are summarized in Table 2.

Although LTR are frequently colonized with Candida, invasive candidiasis is much less common after LT than after other SOTs. The factors predisposing to invasive candidiasis among LTR are not different from those in other SOT recipients (13). These include complicated post-operative hospital stay leading to repeated bacterial infections and increased broad-spectrum antibacterial use, prolonged ICU stays and presence of central venous catheters. Furthermore, LTR requiring extracorporeal membrane oxygenation or those with delayed sternal closure might also be at risk for invasive candidiasis (10).

\section{Outcomes of IFIs}

IFIs, although less common than bacterial infections, significantly influence the all-cause mortality of LTR (2). Mortality rates among LTR with IFI range from $40-82 \%$ 
(17,50-53). The prognosis of disseminated IMI is dismal, with mortality approaching $80 \%$. IFI is an independent risk factor for death after LT in multiple studies (2).

IFIs, particularly invasive aspergillosis, are linked to chronic allograft rejection [bronchiolitis obliterans syndrome (BOS)] (54). BOS is a phenotype of chronic lung allograft dysfunction (CLAD) that manifests as progressive airflow obstruction. Aspergillus colonization, even in the absence of IFI, has also been linked to BOS and BOS-related mortality, independent of rejection $(55,56)$. Colonization with small conidia $(\leq 3.5 \mu \mathrm{m})$ of $A$. fumigatus, $A$. nidulans, A. terreus and $A$. flavipes, in particular, has been associated with BOS and death. In one study, Aspergillus colonization preceded BOS by a median of 261 days. Transcriptional profiling of cell pellets from BAL fluid obtained from surveillance bronchoscopies of Aspergillus-colonized LTRs at 3 or 6-months post-transplant revealed enrichment of expression of genes involved in responses to host defense, inflammation and wounds compared with non-colonized LTR; moreover, expression of genes involved in these processes were significantly associated with progression to CLAD (56). These findings suggest that Aspergillus colonization might cause subclinical injury and subsequent repair that may ultimately lead to CLAD in some LTR. In other studies, however, an association between Aspergillus colonization and BOS was not confirmed $(18,57)$. In one of these studies, LTRs received lifelong inhaled amphotericin $\mathrm{B}$ prophylaxis, a practice that might have modified the risk of BOS. In a multi-center international study of over 900 patients, transplant practices differed between centers and there was no unified therapeutic approach to Aspergillus airway colonization. This heterogeneity of approaches and the use of pre-emptive antifungal therapy at certain centers might have impacted CLAD outcomes (57).

\section{Prevention of IFIs}

Given the high morbidity and mortality of IFIs, LT centers have employed a number of preventive strategies, including universal antifungal prophylaxis (administered to all patients after LT), targeted prophylaxis to a subset of LTRs based on risk factors, and pre-emptive therapy (triggered by surveillance bronchoscopy culture and/or fungal markers). The approaches, advantages and disadvantages of each strategy are summarized in Table 3 (37,58-60).

Universal prophylaxis with a systemic mould-active azole is the most comprehensive strategy $(37,61)$, but it is costly, and associated with drug interactions (e.g., calcineurin inhibitors) and adverse events (e.g., liver toxicity, prolonged QTc with certain triazoles, squamous cell cancer of the skin with prolonged use of voriconazole). Universal prophylaxis with various inhaled amphotericin B formulations is appealing because this mode of administration can deliver a high concentration of antifungal directly to the airway, and at the same time abrogate concerns of systemic adverse events in other organs (58). This approach, however, does not prevent candidiasis, and a recent study revealed high rates of breakthrough pulmonary mould infections with aerosolized ABLC, thus drawing its effectiveness into question (10). Lastly, drug tolerability and outpatient coverage of expensive therapies by third-party payers are potentially problematic with universal prophylaxis. As with any prolonged use of antimicrobial agents, emergence of resistance to systemic and inhaled agents is a concern.

Targeted antifungal prophylaxis is a common approach in liver transplant recipients, because risk factors for IFI are well-defined and relatively easy to monitor in this population. For LTRs, the strongest risk factors in the early post-transplant period are mould culture positivity and airway ischemia, detection of which are dependent upon systematic testing. Risk factors other than colonization and ischemia in LTRs (besides single lung transplant) are less well defined, and they have been identified in some studies and not others. For these reasons, it is difficult to devise comprehensive targeted prophylaxis models. Such models have not been validated in LTRs.

Pre-emptive antifungal therapy based on BAL mould culture and/or fungal biomarkers such as galactomannan (GM) has been attempted in LTR (59). This approach is difficult to adopt in LTR for several reasons. First, the use of screening serum GM and $\beta$-D-glucan (BDG) are flawed by lack of sensitivity and specificity, respectively (62). Therefore, pre-emptive approaches are dependent upon invasive bronchoscopic procedures. Scheduled bronchoscopy is usually performed only 4 to 5 times during the first year of LT, thus early recognition of IMI might be missed if infections develop between bronchoscopies. Furthermore, GM detects Aspergillus but not other moulds. BAL culture sensitivity is less than $60 \%$ even in cases of IFI. Culture positivity of sputum and other respiratory samples is intermittent post-LT, suggesting that failure to detect colonization at a given time point does not preclude that colonization or disease is present.

There are no published studies demonstrating that fungal prophylaxis improves mortality or other outcomes following LT. In a recent abstract, investigators used administrative 
Table 3 Approach in preventing IFI

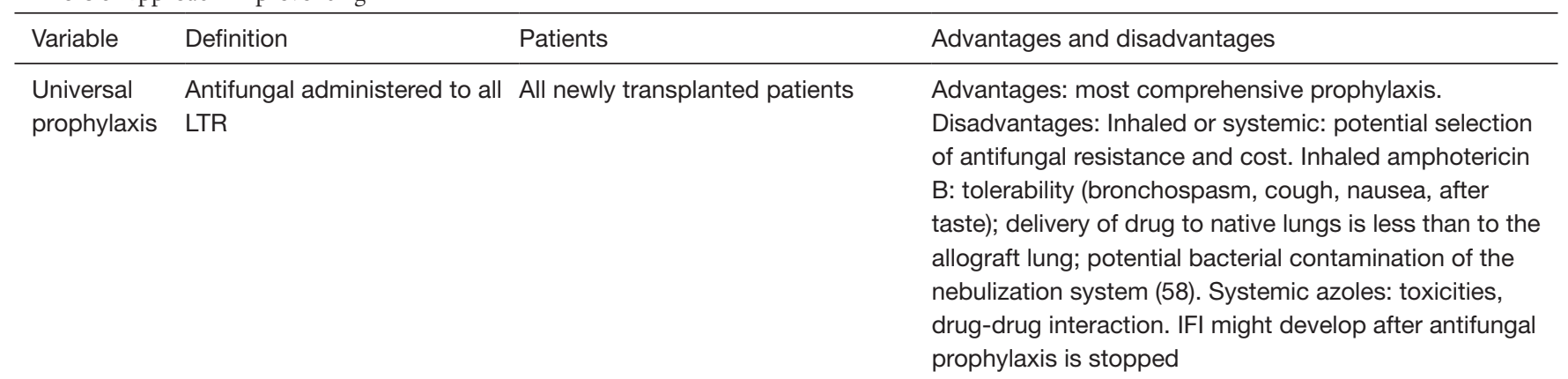

$\begin{array}{ll}\text { Targeted } & \text { Antifungal administered only } \\ \text { prophylaxis } & \text { to subgroups of patients } \\ & \text { at risk for IFI. Note: some } \\ & \text { centers also use targeted } \\ & \text { prophylaxis plus pre-emptive } \\ & \text { therapy }\end{array}$

Pre-emptive Antifungal administered therapy only to patients at risks that (biomarker- are identified by screening driven) with fungal markers (e.g., Aspergillus galactomannan)
Risk group for yeast infection: ECMO, delayed chest closure, etc. Risk group for mold infection: Aspergillus colonization at the time of LT; perhaps pre-LT Aspergillus colonization; single $\mathrm{LT}$, a redo-transplant

Risk groups: positive galactomannan or fungal culture in BAL
Advantages: limiting antifungal use. Disadvantages: knowledge of IFI risk group in LT is still evolving; no prophylaxis for some patients at the period of highest risk of IFI

\begin{abstract}
Advantages: limiting antifungal use. Disadvantage: requires invasive procedure (bronchoscopy and BAL) for fungal culture and galactomannan testing; IFI might develop between scheduled procedurels; sensitivity of both markers might not be optimal leading to delay in initiation of antifungal treatment
\end{abstract}

IFI, invasive fungal infection; LTR, lung transplant recipient; LT, lung transplantation; ECMO, extracorporeal membrane oxygenation.

claims data to determine outcomes of LTRs who received or did not receive prophylaxis (385 and 282 patients, respectively) (61). All-cause mortality was significantly lower in those receiving antifungal prophylaxis versus those who did not (event rate per 100 person-years: 8.77 versus 18.50; hazard ratio, $0.48 ; 95$ percent confidence interval, 0.26 to 0.71; $\mathrm{P}=0.003$ ), and there were lower rates of IFI (event rate per 100 person-years: 15.09 versus 22.48; hazard ratio, 0.68 ; 95 percent confidence interval, 0.45 to $1.05 ; \mathrm{P}=0.08)(61)$. To date, there have not been any studies comparing patient outcome associated with universal prophylaxis versus preemptive therapy.

Given the dearth of clinical evidence, the approach to antifungal prophylaxis varies by LT centers. Over the years, antifungal prophylaxis has evolved as more antifungal agents were introduced to the market and their effectiveness and side effects have become better recognized. In a most recent survey of 44 US LT centers performed between November 2018 and February 2019, antifungal prophylaxis practices shifted more strongly toward universal prophylaxis (5). Most centers used a combined regimen of a systemic triazole and nebulized amphotericin $\mathrm{B}$. The choice of triazole also evolved over time, from fluconazole and itraconazole (popular agents during a survey between 1999 and 2002), to voriconazole and itraconazole (during a survey in 2009), to any mould-active azole (itraconazole, voriconazole and posaconazole) in the most recent survey. At present, virtually no centers use fluconazole (5). Isavuconazole was not mentioned in the latest survey, likely because it was only introduced to the market in the spring of 2015.

The two most recent epidemiological studies of IFI among LTR demonstrated large variations in rates at centers using different universal prophylaxis strategies $(10,37)$. The studies were single center and enrolled a large number of LTRs (815 and 300) (10,37). Standard prophylaxis at the first center consisted of universal inhaled amphotericin B lipid complex (ABLC), with a subset of patients deemed at risk for IFI (i.e., those with delayed chest closure or requiring extracorporeal membrane oxygenation (ECMO) posttransplant, or those with mould colonization pre-transplant) also receiving micafungin or a mould-active azole. Standard prophylaxis at the second center was a mould-active azole (voriconazole or isavuconazole) for all patients. IFI rates at 6 months at these centers were $19 \%$ and $6 \%$, respectively 
(10,37). Moulds accounted for $43 \%$ of IFIs at the first center, and $70 \%$ at the second center. Breakthrough IFI rates while on antifungal prophylaxis were $26 \%$ and $3 \%$, respectively. At the first center, the breakthrough invasive candidiasis rate was $12 \%$ (most cases occurring during micafungin prophylaxis) and the non-Candida IFI rate was $15 \%$ (most breakthrough occurred during inhaled ABLC prophylaxis). At the second center, the invasive candidiasis and non-Candida IFI rates were $1 \%$ and $2 \%$, respectively, with infections evenly distributed among isavuconazole and voriconazole groups. It is difficult to compare data across centers. However, findings of these studies raise the possibilities that inhaled ABLC might be suboptimal in preventing IMIs (10), micafungin may be suboptimal in preventing invasive candidiasis (10), and universal systemic mould active azoles might be more effective as post-LT prophylaxis. Interestingly, $69 \%$ of micafungin breakthrough infections in the first study occurred at extra-blood deepseated sites, suggesting that micafungin pharmacokinetics at these sites might be problematic.

Results of antifungal prophylaxis studies and surveys should be interpreted with caution. First, none of the antifungal drugs have Food and Drug Administration approval for prophylaxis in LTR. Second, surveys merely describe individual center's practice preferences, which may not represent evidence-based approaches. Indeed, several systematic reviews and meta-analyses of antifungal prophylaxis in LT published between 2001 and 2019 failed to offer any insight into the best approach to preventing IFI due to heterogeneity of published studies/trials, high risk of bias and lack of precision (63). The lack of standardized post-LT care poses particular challenges. For example, the use of induction immunosuppression differs between LT centers, and thymoglobulin induction has been linked to higher rate of IFI (64).

In summary, the optimal approach to preventing IFI among LTR is not known. A randomized study comparing the impact of universal with pre-emptive prophylaxis during the early transplant period on LTR outcome would be valuable. However, such trials have not been performed for reasons listed above, and due to justifiable concerns over high fatality rates associated with IFIs. It is also important to note that even in hematologic malignancy populations where several randomized controlled trials have shown that primary antifungal prophylaxis was associated with significant reductions in fungal-related mortality and documented IFIs (65), there are still ongoing controversies about antifungal prophylaxis. Until trials are performed in LTRs, the need for antifungal prophylaxis depends at least in part upon the local rates of IFI, distributions of patients' characteristics, and/or type of induction and maintenance immunosuppression therapy.

\section{Treatment of IFIs}

Optimal management involves early diagnosis and timely initiation of antifungal therapy (66). In selected cases where infected lesions can be resected, surgery should be considered. Furthermore, immunosuppression should be reduced whenever possible. Regarding antifungal management, several guidelines have been published by various organizations, including the International Society for Heart and Lung Transplantation Guidelines for the management of fungal infections (50). The Infectious Diseases Society of America (IDSA) has published specific guidelines for the treatment of aspergillosis (66), candidiasis (67), and other fungal infections including dimorphic fungi. Please refer to appropriate guidelines for antifungal therapy for specific fungi. Our specific recommendations for antifungal therapy for the common IFIs in LTR are summarized in Table 4. Mould-active azoles are frontline agents for treatment of IMIs, with local debridement and inhaled amphotericin B as needed for tracheobronchial disease. Echinocandins and azoles are treatments for invasive candidiasis, in keeping with guidelines in other populations. The major problem with triazoles are inhibitory effects on cytochrome p450 system, leading to increased levels of many drugs including calcineurin inhibitors and inhibitors of mammalian target of rapamycin (mTOR). Therefore, it is of utmost importance to monitor the levels of these inhibitors when co-administered with azoles. The dosages of various mould-active triazoles, the need for therapeutic drug monitoring (68) and agent-specific side effects are summarized in Table 5 .

\section{Conclusions}

In conclusion, IFIs contribute significantly to lung transplant morbidity and mortality. Antifungal prophylaxis is commonly administered, but benefits and optimal regimens are not defined. Universal mould-active azole prophylaxis is used most often. Other approaches include targeted prophylaxis of high-risk LTRs or pre-emptive therapy based on culture or GM (or other biomarker) results. 
Table 4 Therapeutic recommendations for commonly encountered IFIs in lung transplant recipients

\begin{tabular}{|c|c|c|c|}
\hline IFls & Recommended dose & Alternative therapy & Comments \\
\hline \multicolumn{4}{|l|}{ Commonly encountered IFIs } \\
\hline Invasive aspergillosis (IA) & $\begin{array}{l}\text { Voriconazole } 6 \mathrm{mg} / \mathrm{kg} \text { IV. q12h } \\
\times 2 \text { doses, then } 4 \mathrm{mg} / \mathrm{kg} \\
\mathrm{IV} \mathrm{q} 12 \mathrm{~h} \times \text { at least } 7 \text { days; } \\
\text { convert to PO when stable } \\
\text { and trough level is adequate: } \\
200 \mathrm{mg} \text { PO q12h }(>40 \mathrm{~kg}) \text { and } \\
100 \mathrm{mg} \text { PO q12h }(<40 \mathrm{~kg})\end{array}$ & $\begin{array}{l}\text { Isavuconazole } 372 \text { mg IV every } \\
8 \text { h for } 6 \text { doses, then } 372 \text { mg IV/ } \\
\text { PO once daily. Lipid formulations of } \\
\text { Amphotericin B (AmB): liposomal } \\
\text { AmB } 3-5 \text { mg IV daily, or; AmB lipid } \\
\text { complex } 5 \text { mg/kg IV daily. Other } \\
\text { agents: itraconazole } 200 \text { mg PO q8h } \\
\times 9 \text { doses, then } 200 \text { mg BID (need } \\
\text { TDM). Posaconazole } 300 \text { mg (IV or } \\
\text { PO delayed-release tablet) q12h } \times 2 \\
\text { doses, then } 300 \text { mg IV/PO daily }\end{array}$ & $\begin{array}{l}\text { Avoid using voriconazole in severe } \\
\text { cirrhosis. Therapeutic drug monitoring } \\
\text { of voriconazole with ideal targeted } \\
\text { therapeutic voriconazole level } \\
\text { between } 1-5 \mu \mathrm{g} / \mathrm{mL} \text {. For severe or } \\
\text { disseminated IA, combination with } \\
\text { an echinocandin can be considered } \\
\text { (caspofungin } 70 \text { mg IV load then } \\
50 \text { mg IV daily; micafungin } \\
100-150 \text { mg IV daily; or anidulafungin } \\
200 \text { mg IV load then } 100 \text { mg IV } \\
\text { daily). Echinocandin alone is not } \\
\text { recommended for initial treatment of IA }\end{array}$ \\
\hline \multicolumn{4}{|c|}{ Less common IFIs in LTR: yeast infections } \\
\hline $\begin{array}{l}\text { Cryptococcus (pulmonary } \\
\text { and extra-CNS disease) }\end{array}$ & $\begin{array}{l}\text { Severe: Liposomal AmB } \\
5 \mathrm{mg} / \mathrm{kg} \text { IV q24h until } \\
\text { improved, then fluconazole } \\
400 \text { mg PO daily. Mild to } \\
\text { moderate: fluconazole } \\
400 \text { mg PO daily }\end{array}$ & $\begin{array}{l}\text { Mild to moderate: itraconazole } \\
\text { 200-400 mg daily }\end{array}$ & $\begin{array}{l}\text { Low threshold to perform lumbar } \\
\text { puncture for CSF cryptococcal } \\
\text { antigen to rule out CNS involvement }\end{array}$ \\
\hline $\begin{array}{l}\text { Cryptococcus (CNS } \\
\text { infection) }\end{array}$ & $\begin{array}{l}\text { Ambisome } 6 \mathrm{mg} / \mathrm{kg} \text { IV q24h } \\
\text { and flucytosine } 25 \mathrm{mg} / \mathrm{kg} \\
\mathrm{PO} \text { qid for } \geq 2 \text { weeks, then } \\
\text { fluconazole. } 400-800 \mathrm{mg} / \mathrm{d} \\
\times 8 \text { weeks, then fluconazole } \\
200-400 \mathrm{mg} \text { PO daily for } \\
6-12 \text { months as maintenance }\end{array}$ & & $\begin{array}{l}\text { Serum flucytosine levels should } \\
\text { be measured after } 3 \text { to } 5 \text { days } \\
\text { of therapy, with a target 2-hour } \\
\text { post dose level of } 30-80 \mu \mathrm{g} / \mathrm{mL} \text {; } \\
\text { flucytosine levels }>100 \mathrm{mcg} / \mathrm{mL} \\
\text { should be avoided. Fluconazole } \\
\text { dose should be adjusted for renal } \\
\text { function }\end{array}$ \\
\hline \multicolumn{4}{|l|}{ Dimorphic fungi } \\
\hline $\begin{array}{l}\text { Blastomycosis (pulmonary } \\
\text { and extra-CNS disease) }\end{array}$ & $\begin{array}{l}\text { Severe: ambisome } 5 \mathrm{mg} / \mathrm{kg} \\
\text { IV q24h, until stable/improved } \\
\text { then itraconazole } 200 \mathrm{mg} \text { PO } \\
\text { q8h } \times 3 \text { days, then } 200-400 \mathrm{mg} \\
\text { PO daily. Mild-moderate: } \\
\text { itraconazale } 200 \mathrm{mg} \mathrm{PO} \text { q } 8 \mathrm{~h} \\
\times 3 \text { days, then } 200-400 \mathrm{mg} \\
\text { PO daily }\end{array}$ & $\begin{array}{l}\text { Mild-moderate: fluconazole } \\
\text { 400-800 mg PO daily }\end{array}$ & \\
\hline Blastomycosis (CNS disease) & Ambisome 5 mg/kg IV q24h & & \\
\hline
\end{tabular}

Table 4 (continued) 
Table 4 (continued)

\begin{tabular}{|c|c|c|c|}
\hline IFls & Recommended dose & Alternative therapy & Comments \\
\hline $\begin{array}{l}\text { Coccidioidomycosis (CNS } \\
\text { disease) }\end{array}$ & $\begin{array}{l}\text { Fluconazole } 400-1,200 \mathrm{mg} \text { IV/ } \\
\text { PO daily until improved then } \\
\text { fluconazole } 400 \mathrm{mg} \text { daily PO } \\
\text { lifelong }\end{array}$ & $\begin{array}{l}\text { Intrathecal AmB deoxycholate } \\
0.1-1.5 \mathrm{mg} \text {, itraconazole } 200 \mathrm{mg} \text {, } \\
\text { PO q8h } \times 3 \text { days, then } 400-600 \mathrm{mg} \\
\text { q24h }\end{array}$ & \\
\hline \multicolumn{4}{|l|}{ Less common molds in LTR } \\
\hline Mucormycosis & Ambisome $5 \mathrm{mg} / \mathrm{kg}$ IV q24h & $\begin{array}{l}\text { Ambisome IV q24h up to } \\
10 \mathrm{mg} / \mathrm{kg} \text { for severe, CNS } \\
\text { involvement, or worsening infection. } \\
\text { Or posaconazole IV or PO delayed } \\
\text { release tablets } 300 \mathrm{mg} \text { q12h on day } \\
1 \text {, then } 300 \mathrm{mg} \text { daily thereafter }\end{array}$ & $\begin{array}{l}\text { Check posaconazole trough level } \\
\sim 1 \text { week after initiation. Treatment } \\
\text { efficacy is associated with level } \\
>1 \mu \mathrm{g} / \mathrm{mL}\end{array}$ \\
\hline
\end{tabular}

IFI, invasive fungal infection; LTR, lung transplant recipient.

Table 5 Characteristics of mould-active azole agents

\begin{tabular}{|c|c|c|c|c|}
\hline $\begin{array}{l}\text { Mold-active } \\
\text { azoles }\end{array}$ & Dose & Advantage & Disadvantage/toxicities & Note \\
\hline
\end{tabular}

Azole agents: drug-drug interaction due to inhibitory effect on cytochrome p450 system, leading to increased levels of calcineurin inhibitors and inhibitors of mammalian target of rapamycin (mTOR). Major side effect is hepatotoxicity

\begin{tabular}{|c|c|c|c|c|}
\hline Itraconazole & $\begin{array}{l}\text { Available only in } \\
\text { PO formulation. } \\
\text { Solution formulation is } \\
\text { preferred over capsule. } \\
\text { Itraconazole } 200 \text { mg PO } \\
\text { q8h } \times 3 \text { days, then } \\
200 \text { mg PO BID }\end{array}$ & $\begin{array}{l}\text { Potent antifungal against yeast, } \\
\text { dimorphic fungi and Aspergillus. } \\
\text { Solution formulation can be given } \\
\text { via tube feed. SUBA-itraconazole } \\
\text { has improved oral bioavailability. } \\
\text { It has been approved by the FDA } \\
\text { for treatment of aspergillosis, } \\
\text { blastomycosis and histoplasmosis. } \\
\text { Experience in SOT patients is non- } \\
\text { existent at the time of this writing }\end{array}$ & $\begin{array}{l}\text { No activity against } \\
\text { moulds outside } \\
\text { of Aspergillus. IV } \\
\text { formulation is no } \\
\text { longer available. } \\
\text { Erratic absorption of } \\
\text { itraconazole capsule } \\
\text { which might be affected } \\
\text { by } \mathrm{H}_{2} \text { blocker or proton } \\
\text { pump inhibitors }\end{array}$ & $\begin{array}{l}\text { Therapeutic drug monitoring is } \\
\text { recommended. Target trough } \\
\text { level for treatment: } \\
>0.5-1 \mu \mathrm{g} / \mathrm{mL} \text { measured using } \\
\text { HPLC or mass spectrometry }\end{array}$ \\
\hline
\end{tabular}

Table 5 (continued) 
Table 5 (continued)

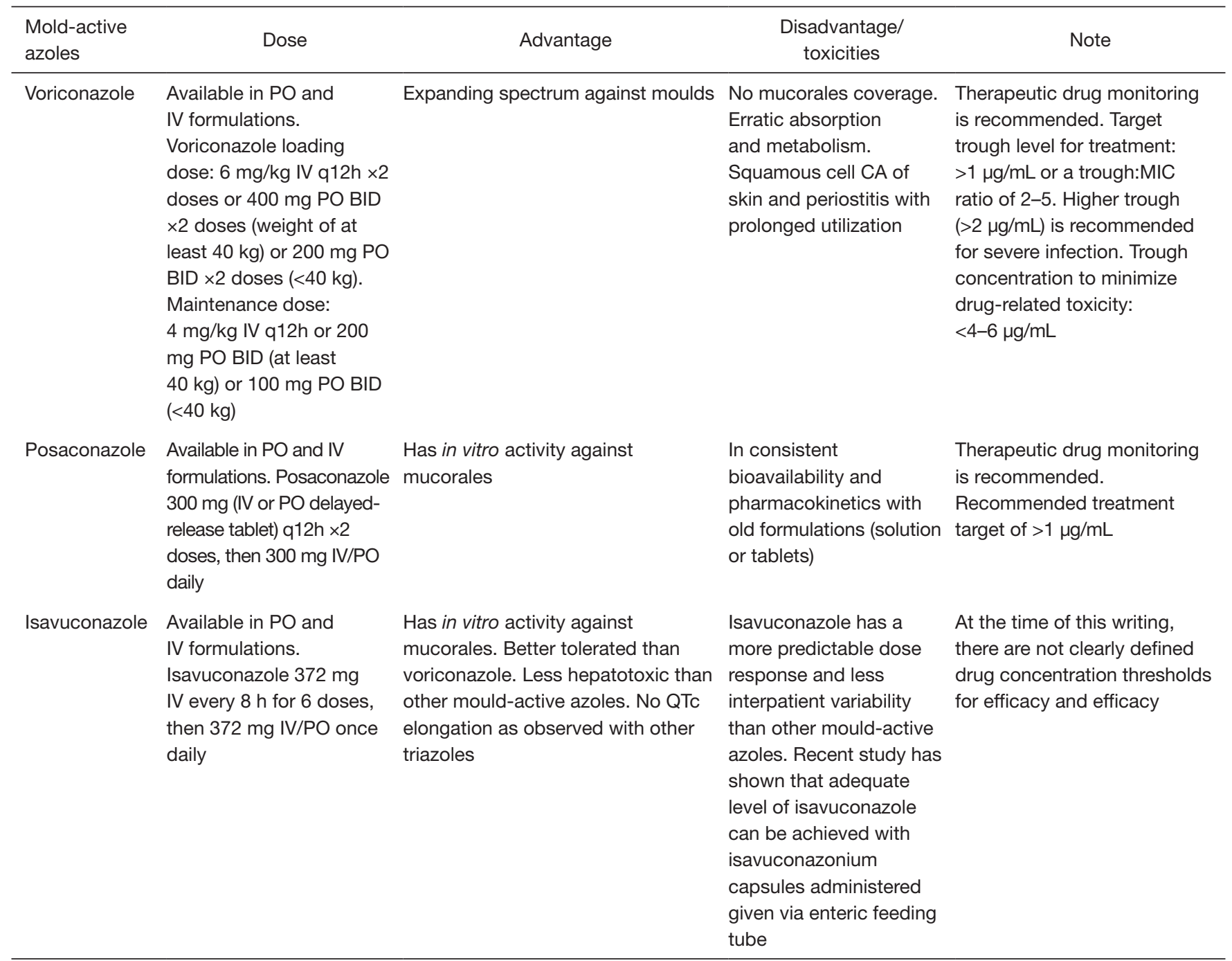

SOT, solid organ transplant.

Prophylaxis trials are needed, but difficult to perform due to heterogeneity in local epidemiology of IFIs and standard LT practices. The key to devising rational strategies for preventing IFIs is to understand local epidemiology in context of institutional clinical practices.

\section{Acknowledgments}

Funding: None.

\section{Footnote}

Provenance and Peer Review: This article was commissioned by the Guest Editor (Jonathan D'Cunha) for the series "Lung Transplantation: Past, Present, and Future" published in fournal of Thoracic Disease. The article has undergone external peer review.

Conflicts of Interest: All authors have completed the ICMJE uniform disclosure form (available at: https://dx.doi. org/10.21037/jtd-2021-26). The series "Lung Transplantation: Past, Present, and Future" was commissioned by the editorial office without any funding or sponsorship. CJC and MHN received Investigator-initiated antifungal research supports from the National Institutes of Health and the Veterans Administration, Astellas, T2Biosystem, Scynexis and Cidara 
Therapeutics. The authors have no other conflicts of interest to declare.

Ethical Statement: The authors are accountable for all aspects of the work in ensuring that questions related to the accuracy or integrity of any part of the work are appropriately investigated and resolved.

Open Access Statement: This is an Open Access article distributed in accordance with the Creative Commons Attribution-NonCommercial-NoDerivs 4.0 International License (CC BY-NC-ND 4.0), which permits the noncommercial replication and distribution of the article with the strict proviso that no changes or edits are made and the original work is properly cited (including links to both the formal publication through the relevant DOI and the license). See: https://creativecommons.org/licenses/by-nc-nd/4.0/.

\section{References}

1. Chong PP, Kennedy CC, Hathcock MA, et al. Epidemiology of invasive fungal infections in lung transplant recipients on long-term azole antifungal prophylaxis. Clin Transplant 2015;29:311-8.

2. Arthurs SK, Eid AJ, Deziel PJ, et al. The impact of invasive fungal diseases on survival after lung transplantation. Clin Transplant 2010;24:341-8.

3. Samanta P, Singh N. Complications of invasive mycoses in organ transplant recipients. Expert Rev Anti Infect Ther 2016;14:1195-202.

4. Menzin J, Meyers JL, Friedman M, et al. The economic costs to United States hospitals of invasive fungal infections in transplant patients. Am J Infect Control 2011;39:e15-20.

5. Pennington KM, Yost KJ, Escalante P, et al. Antifungal prophylaxis in lung transplant: A survey of United States' transplant centers. Clin Transplant 2019;33:e13630.

6. Andes DR, Safdar N, Baddley JW, et al. The epidemiology and outcomes of invasive Candida infections among organ transplant recipients in the United States: results of the Transplant-Associated Infection Surveillance Network (TRANSNET). Transpl Infect Dis 2016;18:921-31.

7. Kauffman CA, Freifeld AG, Andes DR, et al. Endemic fungal infections in solid organ and hematopoietic cell transplant recipients enrolled in the Transplant-Associated Infection Surveillance Network (TRANSNET). Transpl Infect Dis 2014;16:213-24.

8. Pappas PG, Alexander BD, Andes DR, et al. Invasive fungal infections among organ transplant recipients: results of the Transplant-Associated Infection Surveillance Network (TRANSNET). Clin Infect Dis 2010;50:1101-11.

9. Husain S, Sole A, Alexander BD, et al. The 2015 International Society for Heart and Lung Transplantation Guidelines for the management of fungal infections in mechanical circulatory support and cardiothoracic organ transplant recipients: Executive summary. J Heart Lung Transplant 2016;35:261-82.

10. Baker AW, Maziarz EK, Arnold CJ, et al. Invasive Fungal Infection After Lung Transplantation: Epidemiology in the Setting of Antifungal Prophylaxis. Clin Infect Dis 2020;70:30-9.

11. Clark NM, Weigt SS, Fishbein MC, et al. Fungal Infections Complicating Lung Transplantation. Semin Respir Crit Care Med 2018;39:227-54.

12. Kennedy CC, Razonable RR. Fungal Infections After Lung Transplantation. Clin Chest Med 2017;38:511-20.

13. Solé A, Salavert $M$. Fungal infections after lung transplantation. Transplant Rev (Orlando) 2008;22:89-104.

14. Martin SI, Fishman JA; AST Infectious Diseases Community of Practice. Pneumocystis pneumonia in solid organ transplantation. Am J Transplant 2013;13 Suppl 4:272-9.

15. Singh N, Husain S. Aspergillus infections after lung transplantation: clinical differences in type of transplant and implications for management. J Heart Lung Transplant 2003;22:258-66.

16. Minari A, Husni R, Avery RK, et al. The incidence of invasive aspergillosis among solid organ transplant recipients and implications for prophylaxis in lung transplants. Transpl Infect Dis 2002;4:195-200.

17. Singh N, Paterson DL. Aspergillus infections in transplant recipients. Clin Microbiol Rev 2005;18:44-69.

18. Peghin M, Monforte V, Martin-Gomez MT, et al. Epidemiology of invasive respiratory disease caused by emerging non-Aspergillus molds in lung transplant recipients. Transpl Infect Dis 2016;18:70-8.

19. Park BJ, Pappas PG, Wannemuehler KA, et al. Invasive non-Aspergillus mold infections in transplant recipients, United States, 2001-2006. Emerg Infect Dis 2011;17:1855-64.

20. Doligalski CT, Benedict K, Cleveland AA, et al. Epidemiology of invasive mold infections in lung transplant recipients. Am J Transplant 2014;14:1328-33.

21. Vazquez R, Vazquez-Guillamet MC, Suarez J, et al. Invasive mold infections in lung and heart-lung transplant 
recipients: Stanford University experience. Transpl Infect Dis 2015;17:259-66.

22. Lamoth F, Chung SJ, Damonti L, et al. Changing Epidemiology of Invasive Mold Infections in Patients Receiving Azole Prophylaxis. Clin Infect Dis 2017;64:1619-21.

23. George IA, Santos CAQ, Olsen MA, et al. Epidemiology of Cryptococcosis and Cryptococcal Meningitis in a Large Retrospective Cohort of Patients After Solid Organ Transplantation. Open Forum Infect Dis 2017;4:ofx004.

24. Fernández-Ruiz M, Silva JT, San-Juan R, et al. Aspergillus tracheobronchitis: report of 8 cases and review of the literature. Medicine (Baltimore) 2012;91:261-73.

25. Biggs VJ, Dummer S, Holsinger FC, et al. Successful treatment of invasive bronchial aspergillosis after singlelung transplantation. Clin Infect Dis 1994;18:123-4.

26. Birsan T, Taghavi S, Klepetko W. Treatment of aspergillusrelated ulcerative tracheobronchitis in lung transplant recipients. J Heart Lung Transplant 1998;17:437-8.

27. Haidar G, Crespo M, Maximous S, et al. Invasive Tracheobronchial Aspergillosis in a Lung Transplant Recipient Receiving Belatacept as Salvage Maintenance Immunosuppression: A Case Report. Transplant Proc 2016;48:275-8.

28. Palmer SM, Alexander BD, Sanders LL, et al. Significance of blood stream infection after lung transplantation: analysis in 176 consecutive patients. Transplantation 2000;69:2360-6.

29. Palmer SM, Perfect JR, Howell DN, et al. Candidal anastomotic infection in lung transplant recipients: successful treatment with a combination of systemic and inhaled antifungal agents. J Heart Lung Transplant 1998;17:1029-33.

30. Galster W, Morrison PR. Gluconeogenesis in arctic ground squirrels between periods of hibernation. Am J Physiol 1975;228:325-30.

31. Nunley DR, Gal AA, Vega JD, et al. Saprophytic fungal infections and complications involving the bronchial anastomosis following human lung transplantation. Chest 2002;122:1185-91.

32. McGuire FR, Grinnan DC, Robbins M. Mucormycosis of the bronchial anastomosis: a case of successful medical treatment and historic review. J Heart Lung Transplant 2007;26:857-61.

33. Cerceo E, Kotloff RM, Hadjiliadis D, et al. Central airways obstruction due to Aspergillus fumigatus after lung transplantation. J Heart Lung Transplant 2009;28:515-9.

34. Krenke R, Grabczak EM. Tracheobronchial manifestations of Aspergillus infections. ScientificWorldJournal 2011;11:2310-29.

35. Mehrad B, Paciocco G, Martinez FJ, et al. Spectrum of Aspergillus infection in lung transplant recipients: case series and review of the literature. Chest 2001;119:169-75.

36. Della Rocca G, Pierconti F, Costa MG, et al. Severe reperfusion lung injury after double lung transplantation. Crit Care 2002;6:240-4.

37. Samanta P, Clancy CJ, Marini RV, et al. Isavuconazole is as effective as and better tolerated than voriconazole for antifungal prophylaxis in lung transplant recipients. Clin Infect Dis 2021;73:416-26.

38. Singh N. Fungal infections in the recipients of solid organ transplantation. Infect Dis Clin North Am 2003;17:11334 , viii.

39. Lease ED, Zaas DW. Update on infectious complications following lung transplantation. Curr Opin Pulm Med 2011;17:206-9.

40. Nunley DR, Ohori P, Grgurich WF, et al. Pulmonary aspergillosis in cystic fibrosis lung transplant recipients. Chest 1998;114:1321-9.

41. Helmi M, Love RB, Welter D, et al. Aspergillus infection in lung transplant recipients with cystic fibrosis: risk factors and outcomes comparison to other types of transplant recipients. Chest 2003;123:800-8.

42. Paradowski LJ. Saprophytic fungal infections and lung transplantation--revisited. J Heart Lung Transplant 1997; 16:524-31.

43. Luong ML, Chaparro C, Stephenson A, et al. Pretransplant Aspergillus colonization of cystic fibrosis patients and the incidence of post-lung transplant invasive aspergillosis. Transplantation 2014;97:351-7.

44. Aguilar CA, Hamandi B, Fegbeutel C, et al. Clinical risk factors for invasive aspergillosis in lung transplant recipients: Results of an international cohort study. J Heart Lung Transplant 2018;37:1226-34.

45. Vadnerkar A, Clancy CJ, Celik U, et al. Impact of mold infections in explanted lungs on outcomes of lung transplantation. Transplantation 2010;89:253-60.

46. Peghin M, Monforte V, Martin-Gomez MT, et al. 10 years of prophylaxis with nebulized liposomal amphotericin B and the changing epidemiology of Aspergillus spp. infection in lung transplantation. Transpl Int 2016;29:51-62.

47. Neofytos D, Fishman JA, Horn D, et al. Epidemiology and outcome of invasive fungal infections in solid organ transplant recipients. Transpl Infect Dis 2010;12:220-9.

48. Gavalda J, Len O, San Juan R, et al. Risk factors for 
invasive aspergillosis in solid-organ transplant recipients: a case-control study. Clin Infect Dis 2005;41:52-9.

49. Singh N, Limaye AP, Forrest G, et al. Late-onset invasive aspergillosis in organ transplant recipients in the current era. Med Mycol 2006;44:445-9.

50. Husain S, Camargo JF. Invasive Aspergillosis in solidorgan transplant recipients: Guidelines from the American Society of Transplantation Infectious Diseases Community of Practice. Clin Transplant 2019;33:e13544.

51. Hosseini-Moghaddam SM, Ouédraogo A, Naylor KL, et al. Incidence and outcomes of invasive fungal infection among solid organ transplant recipients: A populationbased cohort study. Transpl Infect Dis 2020;22:e13250.

52. Silveira FP, Husain S. Fungal infections in solid organ transplantation. Med Mycol 2007;45:305-20.

53. Patel TS, Eschenauer GA, Stuckey LJ, et al. Antifungal Prophylaxis in Lung Transplant Recipients. Transplantation 2016;100:1815-26.

54. Valentine VG, Gupta MR, Walker JE Jr, et al. Effect of etiology and timing of respiratory tract infections on development of bronchiolitis obliterans syndrome. J Heart Lung Transplant 2009;28:163-9.

55. Weigt SS, Elashoff RM, Huang C, et al. Aspergillus colonization of the lung allograft is a risk factor for bronchiolitis obliterans syndrome. Am J Transplant 2009;9:1903-11.

56. Weigt SS, Wang X, Palchevskiy V, et al. Gene Expression Profiling of Bronchoalveolar Lavage Cells During Aspergillus Colonization of the Lung Allograft. Transplantation 2018;102:986-93.

57. Law N, Hamandi B, Fegbeutel C, et al. Lack of association of Aspergillus colonization with the development of bronchiolitis obliterans syndrome in lung transplant recipients: An international cohort study. J Heart Lung Transplant 2019;38:963-71.

58. Perfect JR, Dodds Ashley E, Drew R. Design of aerosolized amphotericin $\mathrm{b}$ formulations for prophylaxis trials among lung transplant recipients. Clin Infect Dis 2004;39 Suppl 4:S207-10.

Cite this article as: Samanta P, Clancy CJ, Nguyen MH. Fungal infections in lung transplantation. J Thorac Dis 2021;13(11):6695-6707. doi: 10.21037/jtd-2021-26
59. Husain S, Bhaskaran A, Rotstein C, et al. A strategy for prevention of fungal infections in lung transplantation: Role of bronchoalveolar lavage fluid galactomannan and fungal culture. J Heart Lung Transplant 2018;37:886-94.

60. Monforte V, Román A, Gavaldà J, et al. Contamination of the nebulization systems used in the prophylaxis with amphotericin B nebulized in lung transplantation. Transplant Proc 2005;37:4056-8.

61. Pennington KM, Dykhoff HJ, Yao X, et al. The Impact of Antifungal Prophylaxis in Lung Transplant Recipients. Ann Am Thorac Soc 2021;18:468-76.

62. Alexander BD, Smith PB, Davis RD, et al. The $(1,3)\{$ beta\}D-glucan test as an aid to early diagnosis of invasive fungal infections following lung transplantation. J Clin Microbiol 2010;48:4083-8.

63. Pennington KM, Baqir M, Erwin PJ, et al. Antifungal prophylaxis in lung transplant recipients: A systematic review and meta-analysis. Transpl Infect Dis 2020;22:e13333.

64. Shoham S, Marr KA. Invasive fungal infections in solid organ transplant recipients. Future Microbiol 2012;7:639-55.

65. Robenshtok E, Gafter-Gvili A, Goldberg E, et al. Antifungal prophylaxis in cancer patients after chemotherapy or hematopoietic stem-cell transplantation: systematic review and meta-analysis. J Clin Oncol 2007;25:5471-89.

66. Patterson TF, Thompson GR 3rd, Denning DW, et al. Practice Guidelines for the Diagnosis and Management of Aspergillosis: 2016 Update by the Infectious Diseases Society of America. Clin Infect Dis 2016;63:e1-60.

67. Pappas PG, Kauffman CA, Andes DR, et al. Clinical Practice Guideline for the Management of Candidiasis: 2016 Update by the Infectious Diseases Society of America. Clin Infect Dis 2016;62:e1-50.

68. Ashbee HR, Barnes RA, Johnson EM, et al. Therapeutic drug monitoring (TDM) of antifungal agents: guidelines from the British Society for Medical Mycology. J Antimicrob Chemother 2014;69:1162-76. 